followed by IDS is at least a non-inferior strategy for patients with advanced ECa who are unsuitable for primary surgery.

\section{EPV125/\#443 THE PREVALENCE OF UTERUS CANCER IN UZBEKISTAN}

S Djanklich*, Z Sabirdjanova. Republican Specialized Scientific-Practical Medical Center of Oncology and Radiology, Gynecological, Tashkent, Uzbekistan

\subsection{6/ijgc-2021-IGCS. 195}

Objectives To estimate the prevalence of endometrial cancer in Uzbekistan over the last 3 years.

Methods We collected uterine cancer statistical indicators from official statistics in Uzbekistan for the years 2018-2020.

Results Analyzed data of uterina cancer (UC) in 2018-20 years showed that $641(1.4), 640(1,9)$ and $609(1,8)$ UC patients were identified in the Republic, respectively. In 2018 year 315 patients were from the country - side. The patients were into stages as follows: I stage - $31.2 \%$, II stage - 39.9\%, III stage $16.1 \%$, IV - 5.3\%. The mortality rate in 2018 was 0.7 (234 patients) and the 5 -year survival rate consisted $47.3 \%$. The patients were into stages as follows: I stage - 34.8\%, II stage - 41.7\%, III stage - $14.4 \%$, IV stage - 3.1\%. The mortality rate in 2020 was 0.8 (256 patients) and the 5-year survival rate consisted $49.5 \%$. In 2020 the patients were into stages as follows: I stage $-35,8 \%$, II stage $-41,7 \%$, III stage $-11,3 \%$, IV stage - 4,4\%. 568 patients were from the country-side. 5year survival rate consisted $48,7 \%$. The mortality rate in 2020 was 0,8 (274).

Conclusions The morbidity of UC in Uzbekistan has not tend to decrease and requires primary care physicians to promote a healthy lifestyle, a more careful approach to all types of uterine bleeding at women of both fertile and menopausal age. Timely putting diagnosis and treatment of endometrial hyperplastic processes will significantly reduce the number of women at risk for UC.

\section{EPV126/\#448 UNDIFFERENTIATED AND DEDIFFERENTIATED CARCINOMA OF THE ENDOMETRIUM: CLINICOPATHOLOGIC FEATURES AND IMPLICATIONS FOR PROGNOSTICATION AND MANAGEMENT}

${ }^{1} \mathrm{SJ}$ Mah*, ${ }^{2} \mathrm{JY}$ Dong, ${ }^{1} \mathrm{JMV}$ Nguyen, ${ }^{1} \mathrm{~L}$ Bernard, ${ }^{3} \mathrm{~A}$ Lytwyn, ${ }^{3} \mathrm{~J}$ Maxwell, ${ }^{3} \mathrm{D}$ Daya, ${ }^{3} \mathrm{M}$ Sur, ${ }^{1} \mathrm{~L}$ Eiriksson, ${ }^{1} \mathrm{C}$ Reade, ${ }^{1} \mathrm{~V}$ Carlson, ${ }^{1} \mathrm{~L}$ Elit, ${ }^{1} \mathrm{~W}$ Jimenez. ${ }^{1} \mathrm{McM}$ aster University, Juravinski Hospital and Cancer Centre, Gynecologic Oncology, Hamilton, Canada; ${ }^{2}$ Michael G. DeGroote School of Medicine, McMaster University, Medicine, Hamilton, Canada; ${ }^{3}$ McMaster University, Pathology and Molecular Medicine, Hamilton, Canada

\subsection{6/ijgc-2021-IGCS.196}

Objectives Undifferentiated and dedifferentiated endometrial carcinomas (UEC/DDEC) are rare, high grade, and have only been increasingly recognized within the past decade. Studies of their behavior and response to adjuvant to guide prognostication and management are limited. We present the management experience of a single institution.

Methods Using the Juravinski Hospital electronic medical record, we identified all patients with UEC or DDEC treated at our institution from January 2005-December 2020. Clinical information was obtained by chart review.

Results We identified 35 patients with UEC/DDEC; 15 UEC, 20 DDEC. Mean age was 66 years. Only $25.1 \%$ had preoperative endometrial biopsy concordant with final pathology despite $87.5 \%$ review by gynecologic pathologists. Stage distribution was $37.1 \%$ stage I, $14.3 \%$ stage II, $14.3 \%$ stage III, $34.3 \%$ stage IV. $7 / 33$ (21.2\%) had gross residual after surgery; 4 received adjuvant carboplatin-paclitaxel chemotherapy with 2 progressions, 1 partial response and 1 complete response (ORR 50\%). Mean PFS was 11.7 \pm 9.3 months. Fifteen patients had progressive or recurrent disease-of these, 4 were treated with radiation, 3 with chemotherapy (adriamycin, carboplatin-paclitaxel, doxorubicin), and all 7 progressed on treatment. The most common site of recurrence was widely disseminated disease (54.5\%), followed by nodal (18.2\%) and chest (18.2\%). Mean OS was as follows by stage: stage I-II completely resected, 43 months; stage III completely resected, 19 months; stage IV, suboptimally debulked or inoperable, 20 months.

Conclusions UEC/DDEC are aggressive tumours with poor prognoses and remain challenging to diagnose on preoperative biopsy. Platinum-based adjuvant chemotherapy may have some efficacy, however, recurrences respond poorly to salvage.

\section{EPV127/\#500 IMPACT OF COMPUTED TOMOGRAPHY- DETERMINED SARCOPENIA AND ARTIFICIAL INTELLIGENCE-DRIVEN WAIST SKELETAL MUSCLE VOLUME ON SURVIVAL OUTCOME IN ENDOMETRIAL CANCER}

${ }^{1} \mathrm{~A} \mathrm{Seol}^{*},{ }^{1} \mathrm{SI} \mathrm{Kim},{ }^{2} \mathrm{HS}$ Kim, ${ }^{1} \mathrm{HH}$ Chung, ${ }^{3} \mathrm{~J}-\mathrm{W}$ Kim, ${ }^{1} \mathrm{M}$ Lee. ${ }^{1}$ Seoul National University College of Medicine, Department of Obstetrics and Gynecology, Seoul, Korea, Republic of; ${ }^{2}$ Seoul National University Hospital, Department of Obstetrics and Gynecology, Seoul, Korea, Republic of; ${ }^{3}$ Seoul National University College of Medicine, Obstetrics and Gynecology, Seoul, Korea, Republic of

\subsection{6/ijgc-2021-IGCS.197}

Objectives To investigate the impact of computed tomography (CT)-determined sarcopenia and body composition on survival outcomes in patients with endometrial cancer.

Methods We retrospectively identified patients diagnosed with endometrial cancer between 2014 and 2018. Using an artificial intelligence-based tool, the skeletal muscle area $\left(\mathrm{cm}^{2}\right)$ at the third lumbar vertebra (L3) and the skeletal muscle volume $\left(\mathrm{cm}^{3}\right)$ at the waist level from pre-treatment CT scans were measured. These values were converted to the L3 skeletal muscle index (SMI) index and volumetric SMI by normalisation. The relationships between L3, volumetric SMIs, and survival outcomes were evaluated.

Results Altogether, data of 385 patients were analysed. The mean patient age was 55.5 years. Applying the well-known cut-off value for sarcopenia to the L3 SMI, sarcopenia $(<39.0$ $\left.\mathrm{cm}^{2} / \mathrm{m}^{2}, \mathrm{n}=177\right)$ and non-sarcopenia $\left(\geq 39.0 \mathrm{~cm}^{2} / \mathrm{m}^{2}, \mathrm{n}=208\right)$ groups showed similar progression-free survival (PFS; $\mathrm{P}=0.335)$ and overall survival (OS; $\mathrm{P}=0.241)$. Using the median value, the low-volumetric SMI group $\left(<206.0 \mathrm{~cm}^{3} / \mathrm{m}^{3}\right.$, $\mathrm{n}=192$ ) showed significantly worse PFS (3-year survival rate, $77.3 \%$ vs. $88.8 \% ; \mathrm{P}=0.004)$ and $\mathrm{OS}$ (3-year survival rate, $92.8 \%$ vs. $99.4 \% ; \mathrm{P}=0.003)$ than the high-volumetric SMI group $\left(\geq 206.0 \mathrm{~cm}^{3} / \mathrm{m}^{3}, \mathrm{n}=193\right)$. In multivariate analyses adjusted for baseline body mass index and other factors, lowvolumetric SMI was identified as an independent poor prognostic factor for PFS (adjusted HR, 1.762; 95\% CI, 1.0512.953; $\mathrm{P}=0.032$ ) and $\mathrm{OS}$ (adjusted HR, 5.964; 95\% CI, 1.296-27.448; $\mathrm{P}=0.022$ ). 